\title{
The Relationship Between Flipped Learning And Pupils' Performance: A Reflection On Alternative Philosophical Underpinnings
}

\author{
Ismail Mohammed Noriey \& Mohammad Sedigh Javanmiri \\ Department of English, College of Languages, University of Human Development, Sulaimani, Kurdistan Region, Iraq
}

\begin{abstract}
This research paper investigates the significance of the relationship between flipped learning and pupils' academic performance in secondary schools in the Kurdistan Region of Iraq especially with a focus on alternative philosophical underpinnings. Undoubtedly, the significance of this study in the field of educational research bubbles over with controversies. Professional researchers/teachers' disagreements about what happens in schools emanate from the difference in philosophical lenses employed in understanding phenomena, divergent visions regarding the purpose of schooling, and what constitutes an ideal society and cultural differences. This research attempts to understand teachers' perception of reality in classrooms and fathoms the relationship between flipped learning and pupil's academic performance, engagement and achievement. The research methodology employed has focused on mixed methods that allow the data analysis to adopt an interpretive approach and attempted to address the research questions by developing a structured observation and a questionnaire to facilitate the data collection procedure. The findings show that alternative philosophical underpinnings bear profound effects on pupils' learning: teachers and the epistemologies and ontologies employed to understand reality in classrooms significantly impact flipped learning and pupils' academic performance. The results suggest that these implications share common critical statements found in the related literature reviews that also indicate reflections on alternative philosophical underpinnings.
\end{abstract}

Index Terms - Academic Performance, Ontology, Epistemological, Flipped Learning And Philosophical Underpinnings

\section{INTRODUCTION}

Nowadays, arguably every teacher is different; each has their own educational and cultural backgrounds that make them unique. Undoubtedly, the field of educational research is home to many controversies as it accommodates the requirements of ever-changing educational needs as well as professional's disagreements about what should happen in the classroom. This study assumes that, in most instances, the disagreements emanate from the differences in philosophical lenses employed in empathetic understating the phenomenon in education. This study explores some of these philosophical underpinnings.

This research paper is constructed into three main parts: the first focuses on the significance of the relationship between flipped learning and pupils' academic performance according to the strategies used by Kurdish teachers in KRI. Additionally, this study intends mainly to (but not exclusively) describe and critically assess the strengths and weaknesses of the Positivists and Post-positivists paradigms. The main aim is to reflect on the alternative philosophical lenses (including interpretivism, advocacy and pragmatic knowledge claims). Thus, this movement, it is assumed, represents a seismic shift from education being conceptualized as a social process for students to a curriculum-driven, assessment-focused process.

In the second part, the researchers demonstrate that there is no single paradigm that could satisfactorily deal with all the required methodological aspects. Crotty (1998) asserts that every social researcher has two fundamental questions to answer: (1) what methodologies and methods will be employed? And (2) how does the researcher justify the choice of methodologies and methods? Crotty argues that the justification of the choice and use of methodology (the strategy, plan of action, process or design lying behind the use of methods) and methods (the tools, techniques or procedures used to gather and analyze data related to some research question or hypothesis) are informed by our assumptions about the nature of reality ontology - and the theory of knowledge employed to understand that reality -epistemology.

In addition, these assumptions are intertwined with the theoretical perspective (the philosophical stance informing the methodology and providing justification for the context and processes employed). These knowledge claims are sometimes referred to as paradigms (Lincoln et al., 2011, Mertens, 1998) or broadly conceived as research methodologies (Neuman, 2009). Some researchers extend these knowledge claims to include how we write about it -rhetoric- and what values go into its axiology (Creswell, 1994). This allows the researchers to accomplish an understanding of the research problem and the importance of the study in the field of educational sectors. The reasons that the researchers have used mixed methods to evaluate the value of objective and subjective knowledge. In

Journal of University of Human Development

Volume 7 No. 3(2021); DOI: 10.21928/juhd.v7n3y2021.pp104-114

Regular research paper: Received 26 July 2021; Accepted 22 August 2021; Published 24 August 2021

Corresponding author's e-mail: ismail.noriey@uhd.edu.iq, mohammad.javanmiri@uhd.edu.iq

Copyright (02021 Ismail Noriey \& Mohammad Javanmiri. This is an open access article distributed under the Creative Commons Attribution

License (CC BY-NC-ND 4.0) 
part three, the researchers briefly discuss the findings, implications, conclusion, and recommendations.

This basically can help answer these questions: focusing on answering the following main research questions:

1. What are the challenges of flipped learning and their effects on pupils' performance at secondary schools?

2. What are the most significant themes nature of the relationship between flipped learning and pupils' academic performance?

3. To what extent does the teacher significantly impact flipped learning and pupils' academic performance?

\section{Research Objectives:}

$>$ To investigate the impact of flipped learning on students' academic performance at secondary schools in KRI.

$>$ To explore the relationship between flipped learning and pupils' engagement and achievement

$>$ To identify how reflections on alternative philosophical underpinnings alter mindsets and practices of practitioners in education

\section{LITERATURE REVIEW}

This part has three aims: 1) An understanding of the impact of flipped learning on students' academic performance at secondary schools in KRI. 2) A discussion on the significance of the study and the statement of the problem. 3) A good evaluation of the review of the literature to explain the relationship between flipped learning and pupils' engagement and achievement.

\section{Reflection on Teaching and Learning}

As teachers, we have often wondered what goes through the minds of pupils who are being talked at in classrooms in which teachers employ traditional teaching methods -teachercantered classrooms. My (Dr. Ismail's) predicament began when in May 2016, in the UK, I administered a questionnaire to my year 11 higher ability Maths class asking them to relate their classroom and learning experiences. Judging by the 22 mainly hostile answers that I received on this issue, the very thought is unthinkable. My mood was most felicitously caught by one young bright girl who replied:

"My problem is that my History teacher talks too fast for me, and I can't take notes quickly enough... When I manage sometimes to get all the notes from class onto paper, I don't understand what they mean. When I go home to complete my homework, I continue to struggle because what I wrote down in class doesn't seem to match with what I'm supposed to do on my homework."

Another pupil, Anita (not real name), is active in sports, specializing in gymnastics and track. She is a conscientious student who always wants to do her best. Unfortunately, she must often leave school early to travel to games and matches, and she misses a lot of her classes. She informed me when she was in year 10, she tried to keep up with her Maths class, but she just couldn't because she missed so much of it.

She sometimes comes in and meets with her teacher before school, but the teacher is often too busy to individually teach her everything she missed. Gloomily, these scenarios are common across many classrooms. Many struggling pupils who genuinely want to learn fall behind instead. Others are so busy that they miss out on key concepts. Still, others learn how to "play school," but do not really learn important objectives in their courses. We have almost certainly reached an understanding that the traditional model, where teachers stood up and talked at an average of 25 pupils every day, does not meet the needs of all pupils.

The philosophy of teaching which treats children as passive receptacles into which forgettable facts are poured and, accordingly, forces teachers to spend time preparing students for standardized tests (Kohn, 1999) most certainly needs rethinking. Learners (especially children), alternatively, must be helped to become independent, critical, creative thinkers (Robinson and Aronica, 2015). In most schools in England and many other countries, the education systems divide academic disciplines into "subjects," and further divide the subjects into independent units. This fosters an unquestioned illusion that the topics are discrete and unconnected. While this is a serious problem, there is an even more basic failing here: Chances are that the topics themselves have not been covered thoroughly enough because our schools tend to measure out their efforts in increments of time rather than in target level mastery. When the interval allowed for a given topic has run out, it's time to give a test and move on. This has become almost customary in my school and many others in the UK. This for me is unacceptable if not disastrous. This is because concepts build on one another. Algebra requires arithmetic. Trigonometry flows from geometry. If children are provided with a shaky understanding early on, it will lead to complete bewilderment later. Yet teachers prefer to give out passing grades for test scores of 75 or 80 percent. It is basically telling the students that they have learned something that they haven't learned. Students are then hastily nudged on to the next, more difficult unit for which they have not adequately been prepared. The truth is that the educational providers are setting them up to fail. A student who achieves a mark of 75 percent is missing on fully one-quarter of what he or she needs to know (and that is assuming it is on a rigorous assessment). Common sense wouldn't set us on the journey with a car that has one of its wheels faulty.

Modern theories see learning as an individualistic enterprise: learners educate themselves. They learn, first, by deciding to learn, by committing to learning. This commitment allows, in turn, for concentration. All of these processes are active and deeply personal; all involve acceptance of responsibility. Education doesn't happen because an excellent teacher makes a difficult concept easy which puts a smile on a pupil's face (however exciting this might sound). Real education, the researchers of the present study believe, happens in the individual brains of each of us. It requires effort on the part of the learner (as well as the teacher). This claim has found echoing voices. The neuroscientist Kandel (2008) has argued strongly that learning is, in fact, neither more or less than a series of changes that take place in the individual nerve cells of which our brains are composed. 
For far too long accountability process in education has emphasized, and continues to emphasize, school and teacher responsibility (supply-side) to make learning happen and there is nothing wrong with this. We believe, however, that equal emphasis should be placed on learner responsibility (demandside) founded on rigorous incentives and active participation by the learner. This study (without drifting too much) is concerned with philosophical underpinnings of educational research. To address this purpose, this task seems to be incomplete without established philosophical assumptions about what is it that motivates educational actors that researchers intend to investigate - teachers, pupils, parents and policy makers.

\section{A. The significance of the study}

The importance of the study is to state the challenges of flipped learning and their effects on pupils' performance at secondary schools in KRI. A strong underlying conviction, here, is that every teacher is different in their idiosyncratic teaching styles which are largely shaped by their own educational and cultural backgrounds- each teacher is unique. Additionally, the current educational reform efforts have revolved from the soft skills of education to a focus on the measurable outcomes of learning. On the other hand, this research provides an insight to identify the most significant themes that predominantly pervade the nature of the relationship between flipped learning and pupils' academic performance. This is to justify to what extent does the teacher significantly impact flipped learning and pupils' academic performance? Thus, this study is vital because it assumes that, in most instances, the disagreements emanate from the differences in philosophical lenses employed in empathetic understating of the phenomenon in education.

\section{B. Motivations of educational actors}

In analysing educational issues we shall take what has come to be known as the rational choice approach of methodological individualism (Little, 1991, Martin, 1994). The term "rational," as shall be used hence, does not mean brilliant or all-knowing. The educational actors whose behaviour we wish to understand are not gods, so we shall certainly not want to characterize any deviation from godlike behaviour as irrational. The actors we model are ordinary folks who have wants and beliefs both of which affect their behaviour.

Individual wants (which economists refer to as preferences) can be inspired by any number of different sources. Some of these preferences are related to survival and reproduction. Others include religious values, moral precepts, ideological dispositions, altruistic impulses and a sense of common destiny with a family, ethnic group or other community. We do not pretend to know why people want what they want - we leave that to biologists, psychologists and sociologists. Moreover, these specifications are not fundamental to sanction proceeding with this research. Preferences, it is assumed, to be one of the givens of a situation and, for purposes of analysis, the researchers in the present study assume that they don't change much in the shortest possible time.

It can be argued that people who act in accordance with their preferences are self-interested (Martin, 1994). This assumption, notwithstanding, does not inform this research to think of idiosyncratic preferences as selfishness in the very literal meaning of the word. An individual's conception of self might arguably be reflected in his or her preferences and priorities. Pursuit of those preferences and priorities is self-interest at work. It is true that people act under their preferences and therefore are self-interested beings. Nevertheless, preferences, tastes and values are not all there is to rational behaviour. Complementing this world of individual rationality and preferences is the environment in which people find themselves. This external environment is filled with uncertainty (constraints) about how things work, the preferences of others, and random events over which individuals do not have control, or sometimes even knowledge. This uncertainty proves to be crucial since it bears an influence over the way people express their preferences. This underpins the important role of social constructivist philosophy in relation to this research (Lincoln and Guba, 1985, Neuman, 2009, Schwandt, 2000).

Assumptions identified in these works (social constructivists or interpretivists) hold that individuals seek understanding of the world in which they live. They develop subjective meanings of these experiences - meanings directed toward certain objects or things. These meanings are varied and multiple, leading the researcher to look for the complexity of views rather than narrowing meanings into a few categories or ideas. The goal of the research is to rely as much as possible on the participants' views of the situation being studied. The questions become broad and general so that the participants can construct the meaning of a situation, a meaning typically forged in discussions or interactions with other persons. The more openended the questioning, the better, as the researchers seriously attend to what people say or do in their life setting. Moreover, often these subjective meanings are negotiated socially and historically. In other words, they are not simply imprinted on individuals but are formed through interaction with others and through historical and cultural norms that operate in individuals' lives. Here the "processes" of interaction among individuals are crucial. There is also a focus on the specific contexts in which people live and work to understand the historical and cultural settings of the participants. In applying this model to education, we simplify shamelessly in advancing the view that there are mainly two actors within educational settings. First, the consumers of education (pupils, or parents or even governments who buy or demand education using taxpayers' money on behalf of children). For consumers of education, the choice is one of how to spend their monetary endowment and time to maximise their contentment. Second, there are producers of education (teachers, teaching assistants, school leadership, etc.) who possess various productive inputs and must determine how best to combine them to maximise educational outcomes. To keep the model simple, we assume that educational workers toil at a fixed wage rate so that once they decide how much time to spend at work, both their total wages (and hence monetary endowment from which they derive contentment when they transform themselves into consumers) and the amount of time left over for leisure are determined.

Now there is surely ambiguity in each of these ideas, but it is fair to say that from a purely economic perspective, in one fashion or another, theorists might commit themselves to what it is that animates various educational actors. This is not 
because they think their assumptions are verifiable as descriptive statements. Certain obvious questions can help determine that these assumptions are seriously flawed as descriptive statements. Are producers driven entirely by profit motives, or do they give some weight to other things, like the welfare of their workers or the quality of their product? Descriptive accuracy is not the point or purpose of the profitdriven assumptions. The reason is scientific, not substantive. The idea is this: can we explain variations and regularities in educational performance, outcomes, and behaviour with a simple set of assumptions? We strongly believe that we can. The modern theory of economics is a grand intellectual edifice precisely because it has succeeded, as probably no other social science has, in constructing explanations logically, rigorously and in empirically meaningful ways. At the foundation of this edifice is a scientific commitment to explanation, not description.

\section{Flipped learning and Pupils' engagement and achievement}

It is vital to accommodate the needs of all pupils' educational needs. In other words, it is important to construct an awareness of the existence of classrooms that have continued to group pupils by age for which course instructors have struggled to develop effective lessons that reach all levels of students. Researchers and educators have tried to differentiate the delivery of their content, but have noted that as an instructor, it is often difficult to plan for and execute effectively. Furthermore, a great deal of research on the flipped classroom has described increased student engagement and improved student-teacher interactions (Baepler, Walker, \& Driessen: Kong, 2014, p.18). However, as Bishop and Verleger (2013) stated, most of the researchers have explored teacher and student perceptions of flipped learning in the classroom in a small-scale way. Additionally, according to Abeysekera and Dawson (2015), inside the institutions there seems to be an academically sound approach to the effectiveness of flipped classrooms through scrutinizing student engagement that could be encouraged by activities sustaining students' motivation needs. Moreover, Saulnier (2015) suggested that further longitudinal studies control the maintainable effects of the flipped classroom on the ongoing accomplishment of achievement. Besides, one affordance of a flipped learning environment is the ability to reach several different student types at varying cognitive levels. Strayer (2009) showcases a study to see in what ways he could reach more students. He used a mixed-methods study that involved 49 students at the undergraduate level. Strayer involved extensive qualitative surveys in two 10 separate classes. Despite the fact, one classroom was a course taught with a traditional model while another section of the same course was taught with the flipped learning model. However, in the flipped model, Strayer offloaded his lectures by recording them and providing them online- a similar method used in all other studies involved in this review. This is like the current study mixed methods, which can be applied to different student types.

Furthermore, this study assumes that the educational affordances are those characteristics of an artefact. Granting the affordance of reaching fluctuating types of students may be due to how a flipped environment is designed. Using an alike method as Strayer (2009), Davies, Dean, and Ball (2013) endeavoured to find what affordances a flipped environment can provide by using three sections of the same course. Davies, Dean, and Ball (2013) associated a flipped environment, a traditional environment, and a completely self-paced online simulation. Like Strayer, each section covered the same content and used the same assessments. Moreover, the design of the class, fixed activities and complementary instruction could be provided in the flipped environment that could not be in the other two sections. In the qualitative results, the lower-level dependent students noted that having this access to the instructor during class time helped them in understanding the material. According to Abeysekera and Dawson (2015), the students, in the strictly online environment, noted similarly saying they wish they had more access to an expert, such as the instructor. The kind of access to the instructor is one key affordance of a flipped environment that cannot be achieved in the traditional settings.

In several studies (Strayer, 2009; Davies et al., 2013; Murphree, 2014; Rowe et al., 2013; Tune et al., 2013), it was initially difficult to implement a flipped environment. Students found the set-up and design of the class to be slightly fragmented and were initially unenthusiastic. To conclude, the students were unacquainted with this kind of access to the instructor. However, once the students began to view the teacher as a facilitator rather than the instructor (Strayer, 2009), the students eventually became comfortable with asking questions for further understanding regarding flipped learning and their engagement in the classroom.

\section{Positive/Post-positive Knowledge Claims}

There are important complexities that arise when one attempts to explain what positivism is (Polkinghorne, 1983). In comparison to philosophers, researchers across the social sciences and related applied fields such as education have been a little less discerning sometimes with unfortunate consequences. Halfpenny (2014) has noted that "there are so many different understandings about how the term can or should be used" (p.15). Anti-positivists use the term loosely to describe all sorts of disfavoured forms of inquiry. It will pay to set the house in order right at the outset. The present study does not intend to recount the intricacies of the late nineteenth and twentieth-century thought, but it seems that the basic conceptual framework of positivism is built on ideas propounded initially by Bacon, Locke, Hume and Comte. Modern positivists and some post-positivists have added planks and boards of their own, but their additions have hardly altered the basic design of these Founding Fathers. By watching craftsmen at work, Bacon claimed that: (1) only direct observations supply us with statements about the world; and (2) true knowledge is derived from observation statements.

In other words, he rejected the deductive method of the philosophers in favour of sense perceptions. Bacon, however, admitted that the human senses could not always be trusted and that things of the world may not always be what they seem. A scientist could not always trust his senses; he must also rely on 'common sense' and reason. Locke. on his part, believed that all knowledge is posteriori - in other words, it can only be 
derived from sense experience. Knowledge enters the human mind through the organs of sense in the form of sense impressions.

Hume (1962) began his Inquiry Concerning Human Understanding (1748) where Locke has left off. Like Locke, Hume agreed that all human knowledge comes from sense experience and that the mind preserves sense impressions in the form of simple ideas; but he also refined Bacon's insights about the fallibility of human senses and things not being what they seem. This led him to wonder whether causal analysis was in fact possible at all. Hume argued that when we see two events that appear together, we resort to the notion of cause and effect. This raises a dilemma for empiricists, as causality itself cannot be perceived. We can only perceive that $\mathrm{A}$ and $\mathrm{B}$ occur simultaneously. It is our imagination, not our perception, which provides the actual (causal) link between A and B. In other words, our mind is capable of devising theories, which we then impose upon the world. To sum up, four different knowledge claims are implied by both advocates and critics of positivism. These can be sketched in the barest outline:

(1) Comtean-type positivism. The followers of this perspective have an elevated respect for science, and they believe the scientific method could be applied to human affairs, including the study of education. The sciences argued in favour of the focus on observable, objectively determinable phenomena. They regarded all sciences as being related, and as forming a sequence that has developed historically from mathematics, through astronomy, the physical and biological sciences to sociology. Herbert Spencer, John Stuart Mill, Ernst Mach, the logical positivists, and John Dewey, all had a certain affinity with Comtean positivism (Rabinow, 1987).

(2) Logical positivism. This movement sometimes is marked by a great hostility towards metaphysics and adopted the verifiability principle of meaning (Polkinghorne, 1983).

The principle of verifiability stated that something is meaningful if and only if it is verifiable empirically (i.e., directly or indirectly, by observation via the senses). The slogan was "if it cannot be seen or measured, it is not meaningful to talk about." Popper (Popper, 1993) has commented on this endeavour as follows:

"They were trying to find a criterion which made metaphysics nonsense, sheer gibberish, and any such criterion was bound to lead to trouble since metaphysical ideas often [Sic] the forerunners of scientific ones. ${ }^{\prime}(p .80)$

(3) Empiricism. "Positivism" is sometimes used as a label for "empiricism" (mostly by its critics). This for us is a particularly misleading usage.

"Empiricism" refers to a broad spectrum of epistemological positions to the effect: "that either our concepts or our knowledge are, wholly or partly, based on experience through the senses and introspection. The "basing" may refer to psychological origins or, more usually, philosophical justification." (Proudfoot and Lacey, 2009) (p.55)

Within this spectrum, different philosophers mean somewhat different things when they use the term. At any rate it is clear that logical positivism is a type of empiricism and that not all type of empiricism is positivistic. Thus, the so-called "death of positivism" leaves many empiricists unscathed - a point which has been overlooked by some enemies of positivism, to their own cost. The point is that it is difficult to deny some role to empirical data or evidence in the growth of human knowledge; the issue centres on what role. Critics of positivism sometimes get carried away, and in their eagerness to celebrate its so-called demise they throw the empiricist baby out with the positivist bathwater.

(4) Behaviourism. Finally, sometimes the expression "positivism" has been used when the real target is behaviourism. This is probably understandable since the two positions have much in common. The behaviourists favour operationalism - in fact they did much to pioneer it - they are very hostile to abstract theorising in the sciences. A good example is Watson's (1919) assertion that psychologists must abandon the notion of "consciousness" because there were no clear-cut observational criteria for using it. For him only behaviour that is observable, and only by focusing on this can psychology become objective. The opening lines of his paper are notorious: "Psychology, as the behaviourist views it, is a purely objective experimental branch of natural science. Its theoretical goal is the prediction and control of behaviour." (p.457)

In this respect, then, the behaviourists were consistent positivists (and logical positivists at that), but we must emphasize that their rejection of "inner" causes and psychological events seems somewhat misleading. Undoubtedly, this type of positivism has survived and even has been accepted by its critics. However, not all educational and social researchers have been aware of this, and some rough implications have been drawn when they have commented on the death of behaviourism as a type of positivism. To put it bluntly, some of the most celebrated critics of behaviourism are more positivistic than they realise or have some more in common with the positivists than they care to admit. In one form or another, bits and pieces of behaviourism have managed to escape the Grim Reaper. One of its probable constituents which we strongly subscribe to is the idea of rational choice theory (see detailed explanation above) which is very much alive.

Our informed understanding from reading this classic literature is that human knowledge is an insubstantial phenomenon. Because of this we need to treat causal claims made by positivists with great caution.

Strictly speaking, if Hume's advice is to be heeded, social scientists should not try to explain facts; we should be content with describing them and demonstrating their regular appearance. The reason is obvious: patterns and regularities can be observed, causality cannot. We can observe facts. We can observe that, first, one fact (A) appears then another fact (B) appears. But our senses cannot observe any mechanism by which one causes the other. Our imagination, however, can easily conjure up some such mechanism and our reason can make a causal connection credible. This is not to suggest that all observations are relative. In fact, a real world exists and humans perceive this world through self-owned ideas and imagination. This research is practically informed by post- 
positivist thoughts. For example, whilst generally positivists hold that the researcher and the researched person are independent of each other, the present research admits that the theories, hypotheses, background knowledge and values of the researcher can influence what is observed (Reichardt and Rallis, 1994). The conceptual premises that found an approach to objectivity are, henceforth, sanctioned to fashion a recognition of the likelihood of indispensable biases. This, however, only further pinpoints setting up a divergence from the accepted positivist tenets: such establishment informs us that reality can be known only imperfectly and probabilistically because of the researcher's limitations. In effect, in the realm of social science, two types of knowledge can be distinguished. Those based on facts (empirical or positive knowledge) and those based on values (normative knowledge). Empirical knowledge is about facts. It is the foundation of positivistic and postpositivistic science. It consists of knowledge about observable world. It is accessible to all human beings via sensory perception; but that these realities can only be imperfectly known given the significant weaknesses on the part of the observer. These are the core principles of the post-positivistic theoretical framework which underpins this impending study. In the following, several competing frameworks (Crotty, 1998) that continue to shape our understanding of the most relevant anti-positivistic perspectives are presented. They all can come under the umbrella of normative knowledge.

\section{E. Interpretivist knowledge claims}

In contrast to positivists' notion of the social world, interpretivism is based on values and beliefs: this is the realm of individual preferences (Mertens, 1998). Its ontology is based on the precepts that women and men are malleable, and that each of us participates in the construction of our world.

The epistemology subscribes to, in addition to sense perceptions and human reason, relies on the much broader repertoire of epistemological devices such as empathetic and dialectical approaches. Its methodology seeks to identify the socially constructed patterns and regularities of the world. Constructivist or interpretivist ideas originate from Mannheim and from works such as Luckmann's The Social Construction of Reality (Luckmann, 1966) and Guba and Lincoln's Naturalistic Inquiry (Lincoln and Guba, 1985). These theorists convey a basic uncertainty about the world. For them, the world does not exist independent of our senses; it is a world of appearances. More to the point: the world we study is one that appears to people who find themselves situated in different contexts.

Consequently, the world appears different to different observers; its appearances vary with the contextual setting (temporal, geographical, gendered, ideological, cultural etc.). In short, the common point of departure for most constructivists is an agreement that the positivist tradition provides an unsatisfactory basis for social science. On this point, constructivists tend to distance themselves from scientific realists. Interpretivists also agrees that it is important to discuss and consider the nature of the relationship that links the mind and its world. For as long as this relationship remains unsettled, interpretivists and positivists cannot agree about the source of the patterns that both traditions agree to exist and which cry out for explanation. The issue with interpretivism is that it provides no basis for science (at least not in the strict sense of the word), for it is difficult to be certain about this type of knowledge. It is subjective since different individuals tend to entertain different values and beliefs. For example, critical theorists (or emancipatory/advocacy researchers), just like interpretivists utilize a range of qualitative methodologies and methods (such as ethnography, phenomenological research, grounded theory, heuristic inquiry, action research, discourse analysis, feminist standpoint research) yet maintain that their ontological and epistemological knowledge claims stand in stark contrast to that of interpretivism. It is a contrast between research that seeks merely to understand (interpretivism) and a research that challenges (critical theory). "... Between research that reads the situation in terms of interaction and community and a research that reads it in terms of conflict and oppression ... between a research that accepts the status quo and a research that seeks to bring about change" (Crotty, 1998) (p. 113)

Pragmatism, on the other hand, derives its knowledge from the work of Peirce, James, Mead, and Dewey (Cherryholmes, 1988). Recent writers include Rorty (Rorty, 1993), Murphy (Murphy, 1990), Patton (Patton, 1990) and Cherryholmes (Cherryholmes, 1994). For most pragmatists, knowledge claims arise out of actions, situations, and consequences rather than antecedent conditions (as in post-positivism). There is a concern with applications - "what works" - and solutions to problems (Patton, 1990). Instead of methods being important, the problem is most important, and researchers use all approaches to understand the problem (Rossman and Wilson, 1985).

\section{F. The Findings \& Discussion}

This section offers a detailed overview of the main underlying purposes of this mixed-methods study that investigate the significance of the relationship between flipped learning and pupils' academic performance in secondary schools in the KRI. This study has focused on mixed methods that allow the data analysis to adopt an interpretive approach and attempted to address the research questions by developing a structured observation and a questionnaire to facilitate the data collection procedure. The subjects that originally participated in this study included 225 students within 10 secondary schools and close observations of 24 teachers from 4 private and 6 public schools in the KRI[1]. The findings of this study show that alternative philosophical underpinnings have the immense potential to profoundly effect paradigm shifts that can translate to desired quality learning objectives in pupils' learning.

The foremost impact is that teachers significantly impact flipped learning and pupils' academic performance. Furthermore, for the purpose of obtaining and evaluating the objective (this term has been discussed earlier considering postpositivist theories that shroud pure empirical experiences in clouds of biases and personal perceptions) data, three main questions with significant analytical dimensions and a suitable analysis method were prepared and employed. 


\section{G. Factors Analysis}

Factor analysis is the way of releasing many variables into just a few, making it easier to work with the research data. There are always deeper factors to deal with underlying concepts in collected data. Researchers can clarify and work with these instead of working with lower-level variables. For instance, in this research study, two research questions are created to collect data to reach vital information. The questions are: What are the challenges of flipped learning and their effects on pupils' performance at secondary schools? What are the most significant themes nature of the relationship between flipped learning and pupils' academic performance? Through these two factors, a questionnaire was generated to gather data and to analyse them. Factor analysis can only be considered a simple technique. Still, it is also familiar with statistical methods that can be used to clarify the latent factors that deal with noticeable variables.

\section{H. Analysis of Research Questions Data}

There are many different data shapes in the present day, and these data needs to be analysed to make sense. According to Sucky, 2018, "data analysis will not be effective if we do not know what information to infer from the data." The collected data will be appropriately used in studies, but research questions should be well formulated in the first place to get valuable data. After receiving the data, for the purpose of proper data analysis, a number of methods were considered. The process of analysis can generally be divided into two parts: descriptive statistics, and inferential statistics. Descriptive analysis has been used in this research: "Descriptive statistics provide absolute numbers. However, they do not explain the rationale or reasoning behind those numbers" (Bhatia, 2018). Descriptive statistics is a set of techniques used to summarize and present data. It is used for describing a single variable. Bhat states that "Descriptive analysis is also called a "univariate analysis' since it is commonly used to analyse a single variable" (2020).

Furthermore, qualitative data analysis is employed to measure, understand, and analyse the obtained data. Quantitative research is constructed on measurement and is managed in a systematic, controlled manner. Bhandari stated that "Quantitative measurement can be used to find patterns and averages, make predictions, test causal relationships, and generalize results to wider populations" (2020, p.1). Through measures, the researchers will perform statistical tests, analyse differentiation among groups, and decide the effectiveness of treatments.

Measurement is the procedure of observing and writing down the observation gathered as a part of the research effort. In this research study, quantitative measurement is, therefore, used to achieve necessary information when collecting numerical data.

\section{First Question}

What are the challenges of flipped learning and their effects on pupils' performance at secondary schools?

The findings of research question one was very interested in the sense that they shed light on the challenges of flipped learning which impact students' performance at school. Table (1) has shown the four main challenges in which 23 out of 24 teachers candidates' interviews were mentioned correspondingly.

(Table 1)

The four main challenges)

\begin{tabular}{|c|c|c|}
\hline \multicolumn{2}{|c|}{$\begin{array}{l}\text { The challenges of flipped learning and their } \\
\text { effects on pupils' performance at schools }\end{array}$} & \multirow{2}{*}{$\begin{array}{c}\begin{array}{c}\text { Total } \\
(\mathrm{n}=24)\end{array} \\
22\end{array}$} \\
\hline Managing Emotions: & ction & \\
\hline Understanding emotions in & Learning & 19 \\
\hline Create a Mindset for Behavi & our & 21 \\
\hline Academic Results & & 23 \\
\hline
\end{tabular}

The above table is about the first research question that addresses four main challenges of flipped learning which impact students' performance at schools. First, the majority (22 out 24) of teacher respondents have chosen to show managing a reaction as a major challenge. Thus, emotions often can be managed in the classroom successfully if the teachers will do so. Moreover, within the person's sensitive comfort zone, managing emotions necessitates the management of one's own emotions as well as others' emotions to encourage one's own and others' personal and social goals. In so much the same way, using flipped classrooms with alternative learning goals will help teachers to make recommendations for improvement and implementation of successful flipped classrooms within different educational environments. This is excellent support for teachers to manage the reaction.

The second challenge calls for a deep understanding of the crucial need of considering emotions in learning. A majority of the respondents (19 out of 24 ) have mentioned that understating emotions is vital in teaching.

Emotions convey their pattern of possible messages in the classroom as well as actions associated with those messages. For instance, poor participation by a student in a particular subject means that the student feels alien to the group or the course in general in the classroom. This is an established area of focus in the flipped learning environments. It shows in Graphic 1 below: 


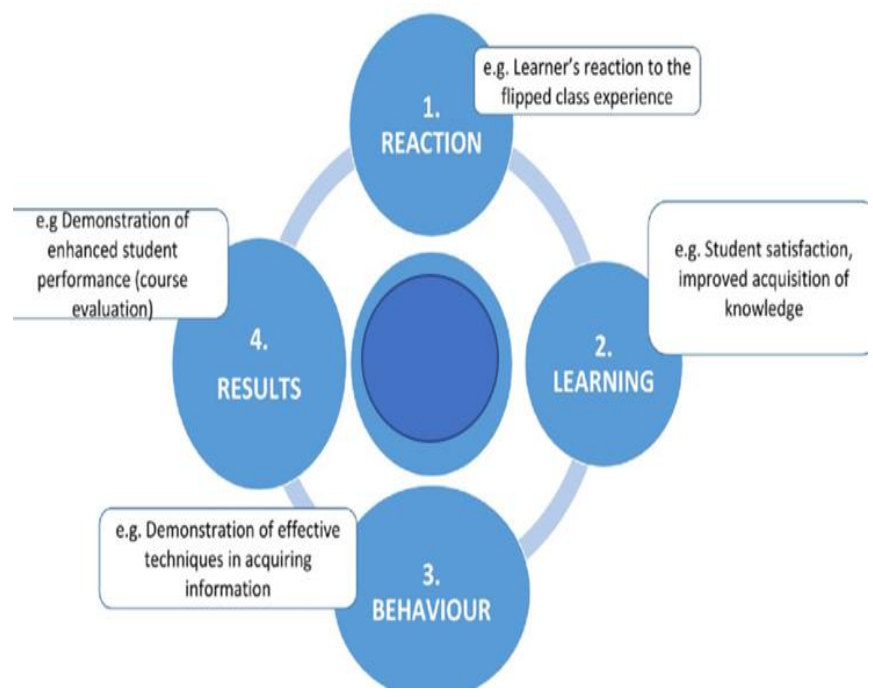

Graphic (1)

(The four main challenges)

The third challenge: 21 out of 24 teachers were shown to mention the prominence of the knowledge of using emotions to facilitate thoughts and behaviours in the classrooms. This was the capacity of the reactions to guide the cognitive system and promote thinking and help direct thinking toward truly vital matters. A14, one of the participants, mentioned that "it is difficult to imagine effective teachers who do not have an abiding facilitating thought, who does not love being among students, and who do not gain fulfilment from nourishing others minds and lives".

Dubiously, A 22, another participant, pointed out a similar problem to A 18. Educational workers and facilitators, especially teachers, are expected to show mastery of the skills that incorporate emotions in designing action plans that create mindsets for behaviour. The fourth challenge is noticing academic results: 23 out of 24 participants were identified. It is so significant that teachers focus on this challenge which is leading the dimensions to accurately perceive academic results in schools. For example, providing an ambience where students find positive images of themselves that effect valuable recognition of their very existence in classroom settings. This is most conspicuous insofar as it acts as a powerful drive that encourages positive mentalities with foremost achievement of academic goals. A 21 has stated that "a positive mind-set can give me more confidence, improve my mood, and even reduce the likelihood of developing conditions such as depression and other stress-related disorders that cannot start the day with a positive affirmation."

\section{Second Question}

What are the most significant themes that characterize the nature of the relationship between flipped learning and pupils' academic performance?

The data collected from questionnaires were used to investigate the significance of flipped learning in learning environments (classrooms here) where teachers can potentially influence the students' performance as well as academic achievement. Quantitative data were collected using online questionnaires to identify and specify the dimensions of the most significant themes that characterize the relationship between flipped learning and pupils' academic performances and achievements. The findings of research question two show that there are five most significant impacts of the relationship between flipped learning and pupils' academic performance. From Graphic 2, it becomes clear and concise that there are five main significant factors.

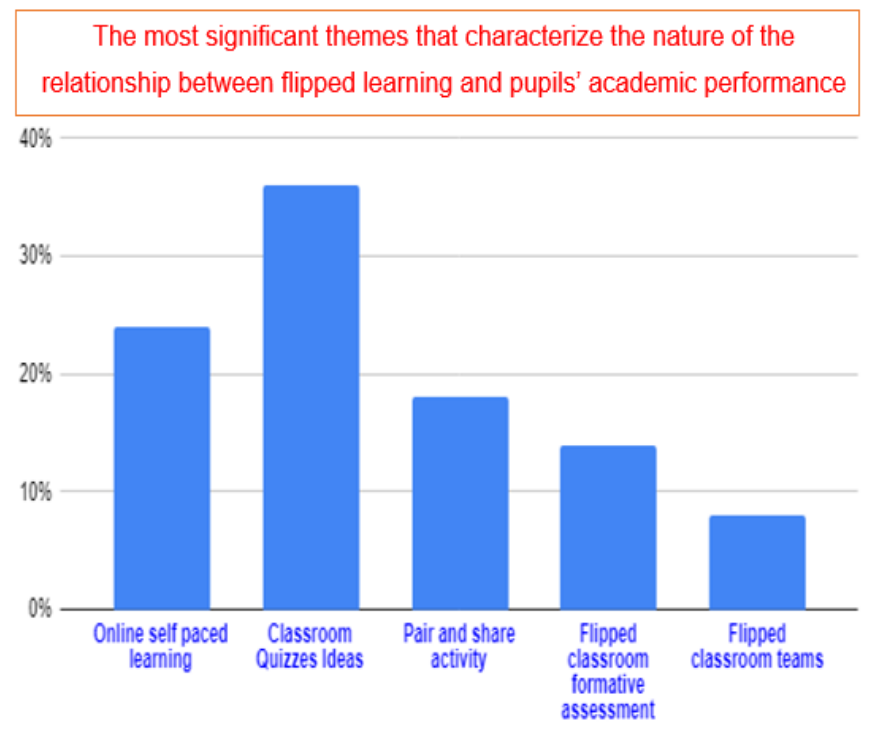

(Graphic 2)

(The five most significant themes that characterize the nature of the relationship between flipped learning and pupils' academic performance)

Inside graphic 2, it has shown that five factors impact the relationship between flipped learning and pupil's academic performance. First, (36\%) the majority of teachers responded that classroom quizzes and continual assessments impact pupils' academic performance. A13 stated that "this is very important for the flipped learning and students' academic results." The second factor is online self-paced learning with (24\%) advocates among the respondents. Offering self-placed online learning is key to empowering the learners with access to easily digestible content anytime, anywhere. This flexibility, which is inherently available in online self-paced learning, offers a new universe of opportunities to deliver continuing education that is in comfortable alignment with the needs of today's learners. The third important theme, pair and share activity, has shown to have won favours with $18 \%$ (that is 24 teachers' responses coded and adapted in percentage) of the respondents.

A11 pointed out that "it is significant to this factor in flipped learning classroom because the pair-share activity allows them to feel more comfortable sharing their thoughts." In addition, this strategy can further improve students' speaking and listening skills. The fourth factor is flipped learning classroom, which $(14 \%)$ of teachers believe is successful. A16 has mentioned that "the flipped classroom is a blended learning model in which traditional ideas about classroom activities and homework are revised, or flipped. In this model, teachers have students interact with new material for homework first." Finally, the fifth factor is the flipped learning teams that are the 
lowest coding from the results $(8 \%)$ have mentioned. It improves personalized learning and teaching methods.

\section{Third Question}

To what extent does the teacher significantly impact flipped learning and pupils' academic performance?

The findings for research question three were compound because two forms of data were essential to be accomplished. In the first form, 24 teachers were interviewed. The second form, the questionnaire, was distributed among 225 students from 10 schools optionally selected. Table 2 has shown the four main factors that extend the significance of the teachers' impact on flipped learning classrooms and pupils' academic results.

(Table 2)

The four main Factors impact Flipped Learning)

\begin{tabular}{|l|c|c|}
\hline $\begin{array}{c}\text { The four main Factors impacts } \\
\text { Flipped Learning }\end{array}$ & $\begin{array}{c}\text { Total } \\
(\mathrm{n}=24)\end{array}$ & $\begin{array}{c}\text { Total } \\
(\mathrm{n}=225)\end{array}$ \\
\hline Pupils Remembering & 23 & 216 \\
\hline Pupils Applying Tasks & 21 & 211 \\
\hline Pupils Creating & 22 & 209 \\
\hline Pupils Analyzing & 23 & 201 \\
\hline
\end{tabular}

\section{Pupils'Remembering}

First, 23 out of 24 , the majority of teachers responded that flipped classroom influences pupils' remembering: this bears substantial effects on pupils' academic performance. According to A 15: "the terms flipped classroom and flipped learning have been on my detector for a while now and I have always thought it sounded an interesting concept for remembering tasks by pupils." Moreover, A 19 pointed out that by using flipped classrooms, educators can use the extra instructional time to create an active environment with the students where there is constant feedback available for the students.

\section{J. Pupils Applying Tasks}

The second factor is applying tasks in the flipped classroom: 21 out of 24 candidates were respondents to this concept. The concept is to apply tasks in a flipped classroom where students engage with teachers or other materials outside of class to prepare for an active learning experience in the classroom. Thus, pupils do not need to memorize everything. It means pupils can study in the flipped classroom and understand well without the necessity to memorize the tasks. A17 believes that "an increasing number of teachers in different schools are using flipped classroom approach in their teaching." This instructional approach combines video-based learning outside the classroom and in-application applying in group learning activities inside the classroom. Lastly, the researchers of this study assume the purpose of this factor is to provide a review of implementing flipped classrooms that were identified and categorized into pupils related applying tasks.

(Table 3)

Schools Demographics)

\begin{tabular}{|c|c|c|c|c|}
\hline $\begin{array}{l}10 \text { Schools } \\
223 \text { students }\end{array}$ & Gender & $\begin{array}{l}\text { Level of } \\
\text { Education }\end{array}$ & $\begin{array}{l}\text { Education } \\
\text { Rank }\end{array}$ & Key Stages 3,4 and 5 \\
\hline 1. Slemani High School & $\begin{array}{l}\text { Male \& } \\
\text { Female }\end{array}$ & Secondary & 2 & Year 10 \\
\hline 2. Zanst Private high school & $\begin{array}{l}\text { Male \& } \\
\text { Female }\end{array}$ & Secondary & 1 & Year 10 \\
\hline $\begin{array}{l}\text { 3. Baxshnda Secondary } \\
\text { School }\end{array}$ & Male & Secondary & 1 & Year 11 \\
\hline 4. Tavan High School & Female & Secondary & 1 & Year 12 \\
\hline $\begin{array}{l}\text { 5. US Colleges Secondary } \\
\text { School }\end{array}$ & $\begin{array}{l}\text { Female \& } \\
\text { Male }\end{array}$ & $\begin{array}{l}\text { Academic } \\
\text { Institution }\end{array}$ & 2 & Year 11 \\
\hline 6. Salahadin High School & Male & Secondary & 1 & Year 10 \\
\hline 7. Rava Institute & Male & Secondary & 2 & Year 11 \\
\hline $\begin{array}{l}\text { 8. Computer Institute in } \\
\text { Slemani }\end{array}$ & \begin{tabular}{|l} 
Female \& \\
Male \\
\end{tabular} & $\begin{array}{l}\text { Academic } \\
\text { Institution }\end{array}$ & 2 & Year 11 \\
\hline 9. Amyan Institute & $\begin{array}{l}\text { Male \& } \\
\text { Female }\end{array}$ & $\begin{array}{l}\text { Academic } \\
\text { Institution }\end{array}$ & 2 & Year 10 \\
\hline $\begin{array}{l}\text { 10. Technical Institute of } \\
\text { Bakrajo }\end{array}$ & Male & Secondary & 3 & Year 10 \\
\hline
\end{tabular}

Table 3 above has shown schools demographics and compounds with table 2. The compound from both data analyses the findings has found four main factors that impact flipped learning in applying tasks.

\section{K. Pupils Creating}

(22 out of 24) teachers were interviewed and this factor enables teachers to move much more quickly from focusing on pupils creating the tasks to develop higher-order thinking skills like evaluation and analysis. In addition, as stated by A 12 "this is a perfect way of encouraging pupils creating own developing possession of learning by the students themselves."

The value of a flipped class is creating a workshop where students can inquire about lesson content, test their skills in applying knowledge, and interact in hands-on activities. Additionally, having a flipped classroom means that creating tasks, in-class assignments, and essays into more engaging discussions and projects.

\section{Pupils Analysing}

The fourth theme regards pupils' analysing tasks in flipped learning. The main goal of this factor, in a flipped classroom, is to enhance student learning and achievement by reversing the traditional model of a classroom through re-focusing class time 
on analysing; lessons, assessments, and homework which are leading the improvement become incentives for the pupils to prepare for analysing tasks. Finally, the flipped learning classroom encourages pupils to analyse the interaction and this study suggests that it is one of the most important pedagogical formats that can improve student learning in flipped learning classroom.

\section{Results and Discussion}

The findings of this study show that alternative philosophical underpinnings can have profound effects on pupils' learning. The first effect is that the teacher significantly impacts flipped learning and pupils' academic performance. The second finding signifies the validity of epistemological and theoretical assumptions: the relationship between flipped learning and pupils' academic performance. The third implication sheds light on the ontology and the theory of knowledge employed to understand the reality in the classroom in a variety of approaches. Moreover, as detailed above, the theoretical framework that the present research promotes to have the quality to brighten and justify the objectives of this study is the post-positivistic or scientific method framework. Post-positivist researchers possibly need to recognise, sometimes reluctantly, that the core principles of positivism must be relaxed. Positivism reflects a deterministic philosophy in which causes probably determine effects or outcomes. Hence, the problems studied by positivists reflect a need to examine causes that impact outcomes. It is also reductionist in that the intent is to decrease the models into smaller, discrete sets of relationships that are capable of being tested in terms of the variables that constitute hypotheses and research questions. The knowledge that develops through a positivist or post-positivist lens is based on careful observation and measurement of the objective reality that exists "out there" in the world. Nevertheless, one does not need to operate within the positivistic research framework to say something about causality. Although qualitative methods do not show to own a causal warrant, in a situation where the researcher makes explicit that he/she does not intend to report counterfactual causal findings, it is perfectly alright to explain the causes of social events through constructivist or interpretive framework employing qualitative methods. Because of the issue of unravelling counterfactual causes in social science research, social methodologists are currently suggesting a new paradigm which is receiving a lot of sympathy i.e. causal social explanation methodology.

Quantitative and qualitative methods are not alternative strategies for the same research activity; it is unfortunate that researchers continue to emphasize the "false dualism" between the two. The methodological battle within the social sciences has contributed to a growing feeling within the educational research community that the positivistic model is inadequate for the study of education. Several theorists have rightly suggested that the aims of social science are different from those of naturalistic science. Some have argued that whereas naturalistic science aims at explanation in terms of prediction and control, social science aims at understanding. Educational research in the naturalistic (or positivistic) mode can rarely tell us everything about, for example, a particular pedagogical method - say, one of teaching "quadratic equation" - and possibly why it is significantly and generally better than another. Qualitative methods - ethnographic studies, case studies, historical summaries, even powerful anecdotes - can help us understand why a method works with some children and some teachers in some situations and fails to do so in others.

The researchers of the present study suggest that there is a need to acknowledge that what has happened in educational research has all the earmarks of a scientific revolution. Important figures, long associated with positivistic paradigm, have acknowledged qualitative aspects previously ignored in naturalistic science. Qualitative researchers have polished their work on category schemes to increase the possibility of generalization. Consequently, quantitative methods have become more qualitative and vice versa. It may be that what some think of now as a "qualitative" paradigm will not displace the old but, rather, that a new paradigm incorporating the best of each will emerge. The present research contends that both paradigms have much to offer, but what is offered and what constitutes the goals of any project must together guide the choice of methodology. Whether the intention is to build or test a theory or to survey an issue or look at it in depth or to look at individual cases and abstract essential features, generalizing them because of their perceived vital nature would all go into making decision on what methodology and data collection methods one adopts in a specific study. There is no intention to argue here that one paradigm is better than another in a variety of given situations. The present study, therefore, complements this methodology with a case-study design to help the researchers of this study understand the perceptions of actors within the education community they are investigating.

This enables the present researchers to become categorized as post-positivist thinkers in the field of planning quality education plans. Notwithstanding, a certain inclination towards pragmatism is inherently structured into our efforts as our research seeks to bear practical achievements. Combined, they might further classify the present researchers' rationale as methodological pluralist. The result is to dismember the body of hard facts to identify the multi-dimensional significances of disentangled empirical observations insofar as they bear proof of relevance to unravelled counter facts. Paradigm shifts are the result of novel epistemological interpretations with the potential to facilitate the learning process and help achieve the target educational goals.

The challenges of flipped learning help educators and learners better understand the complex cobweb of learning; it is predominately a result of dealing with the human mind, feelings and emotions in the very act of education. Educational workers, especially teachers, need to develop an awareness of the important emotional dimension of the learners and constantly fine-tune their understanding of the condition of human nature, feelings and emotions. This is in favourable agreement with the ever-changing nature of the modern world. The rapid shifts need to be observed, understood and interpreted while heeding to the foremost needs of an important education stakeholder, the pupils as in our study. The outcome includes better 
understanding and better management of emotions in flipped learning environments.

\section{REFERENCES}

Bergmann, J. \& Sams, A. (2012). Flip your classroom: Reach every student in every class every day, International Society for Technology in Education.

Bergmann, J. \& Sams, A. (2014). Flipped learning: Gateway to student engagement, International Society for Technology in Education.

Bransford, J. D., Brown, A. L. \& Cocking, R. (2000). How people learn: Brain. Mind, Experience, and School, 2.

Brunsell, E. \& Horejsi, M. (2013). Flipping Your Classroom in One" Take". The Science Teacher, 80, 8.

Cherry Holmes, C. H. (1988). Power and criticism poststructural investigations in education.

Cherry Holmes, C. H. (1994). More notes on pragmatism. Educational researcher, 16-18.

Creswell, J. W. (1994). Qualitative and quantitative approaches. Qualitative and quantitative approaches.

Crotty M. (1998). The foundations of social research: Meaning and perspective in the research process, Sage.

DE vaus, D. A, vaus, D (2001). Research design in social research, Sage.

Halfpenny, P. (2014). Positivism and Sociology (RLE Social Theory): Explaining Social Life, Routledge.

Herreid, C. F. \& Schiller, N. A. (2013). Case studies and the flipped classroom. Journal of College Science Teaching, 42, 62-66.

Hua, L. V., Goodwin, D. \& Weiss, A. (2013). Traditional vs. Blended Learning of Pharmacology. Optometric Education, 39, 28-34.

Hume, D. (1962). A treatise of human nature. Book 1: Of the understanding, Meridian.

Kandel, E. R. (2008). Psychiatry, psychoanalysis, and the new biology of the mind, American Psychiatric Pub.

Kohn, A. (1999). The schools our children deserve, Boston: Houghton Mifflin.

Kohn, A. (2007). The homework myth: Why our kids get too much of a bad thing, Da capo press.

Levacic, R. (2005). Educational Leadership as a Causal Factor: Methodological Issues in Research on Leadership" Effects". Educational Management Administration \& Leadership, 33, 197-210.

Lincoln, Y. S. \& Guba, E. G. (1985). Naturalistic inquiry, Sage.

Lincoln, Y. S. Lynham, S. A. \& Guba, E. G. (2011). Paradigmatic controversies, contradictions, and emerging confluences revisited. The Sage handbook of qualitative research, 4, 97-128.
Little, D. (1991). Varieties of social explanation: An introduction to the philosophy of social science.

Luckmann, T. (1966). The social construction of reality: A treatise in the sociology of knowledge, Anchor Books.

Martin, H. (1994). The philosophy of social science-an introduction. Cambridge University Press.

Mertens, D. M. (1998). Research methods in education and psychology: Integrating diversity with quantitative \& qualitative approaches.

Murrhy, J. P. (1990). Pragmatism: From Peirce to Davidson, Westview Pr.

Neuman, W. L. (2009). Social research methods: Quantitative and qualitative methods. Allyn \& Bacon.

Patton, M. Q. (1990). Qualitative evaluation and research methods, SAGE Publications, inc.

Pirie, S. E. (1996). Classroom Video-Recording: When, Why and How Does It Offer a Valuable Data Source for Qualitative Research?

POLKINGHORNE, D. 1983. Methodology for the human sciences: Systems of inquiry, Suny Press.

Popper, K. (1993). Unended Quest: An Intellectual Autobiography, Karl Popper, London: Routledge.

Pring, R. (2004). The Philosophy of Education, Bloomsbury Publishing.

Proudfoot, M. \& LACEY, A. R. (2009). The Routledge dictionary of philosophy, Routledge.

Rabinow, P. (1987). Interpretive social science: A second look, Univ of California Press.

Reichardt, C. S. \& RALLIS, S. F. (1994). The QualitativeQuantitative Debate: New Perspectives. New directions for program evaluation, 61, 1-98.

Robinson, K. \& Aronica, L. (2015). Creative Schools: Revolutionizing Education from the Ground Up, Penguin UK.

Rorty, R. (1993). Feminism, ideology, and deconstruction: A pragmatist view. Hypatia, 8, 96-103.

Rossman, G, B. \& Wislon, B. L. (1985). Numbers and words combining quantitative and qualitative methods in a single large-scale evaluation study. Evaluation Review, 9, 627-643.

Schwandt, T. A. (2000). Three epistemological stances for qualitative inquiry. Handbook of qualitative research, 2, 189-213.

Watson, J. B. (1919). Psychology: From the standpoint of a behaviourist, Lippincott. 